\title{
The safety and efficacy of the trans- umbilical approach for pyloroplasty in the management of post-acid corrosive gastric outlet obstruction in children
}

Essam A. Elhalaby ${ }^{1 *}$ (D) Nezar Abd Erouf Abo Halawa ${ }^{1}$, Ismael E. Elhalaby ${ }^{1}$, Dina Shawky ${ }^{2}$, Hussam Hassan ${ }^{1}$ and Hisham A. Almetaher'

\begin{abstract}
Background: Gastric outlet obstruction (GOO) may follow acid corrosive ingestion. Several surgical techniques have been reported after the failure of endoscopic dilatation. The aim of this study was to evaluate the feasibility and safety of Heinecke-Mikulicz pyloroplasty (HMP) through a circum-umbilical skin incision in children with pyloric stricture after accidental acid corrosive ingestion.

Results: Seven patients were males and 4 were females, their ages ranged from 17 months to 6 years at the time of definitive treatment. The surgery was completed successfully in all patients through the circum-umbilical incision. Vertical extension of skin incision was needed in one patient. The pylorus was grossly affected in 9 patients. Both pylorus and gastric antrum were involved in 2 patients. Nine patients had an excellent postoperative course with the cessation of vomiting and progressive weight gain. One patient developed postoperative recurrent stricture treated by gastrojejunostomy. Another patient with associated esophageal stricture responded to repeated endoscopic dilatation for the esophageal stricture and pyloroplasty for the pyloric stricture. No surgical site infection or wound dehiscence occurred in any patient.

Conclusion: Heinecke-Mikulicz pyloroplasty through a circum-umbilical approach is both feasible and safe in the majority of children with post-acid corrosive GOO. It is associated with satisfactory wound healing and excellent cosmetic outcome. Different techniques are recommended in cases of severe pyloric stricture associated with significant proximal gastric antral scarring.
\end{abstract}

Keywords: Gastric outlet obstruction, Pyloroplasty, Acid corrosive injury, Circum-umbilical incision

\section{Background}

Accidental corrosive ingestion by children still occurs in some developing countries [1]. Children are more vulnerable to corrosive injury due to the easy availability of corrosive material in the market, lack of parental supervision, and incorrect storage of these chemicals at home $[2]$.

\footnotetext{
* Correspondence: eselhalaby@gmail.com; essam.elhalaby@med.tanta.edu.eg

${ }^{1}$ Pediatric Surgery, Faculty of Medicine, Tanta University Hospital, Tanta

University, Tanta, Egypt

Full list of author information is available at the end of the article
}

Gastric injury after corrosive ingestion is relatively uncommon as compared to esophageal injury. Gastric outlet obstruction (GOO) is a significant complication of corrosive acid ingestion [3]. In contrast to post-corrosive esophageal injury, limited series reporting the sequel of acid ingestion on the stomach have been published [4-9].

It is generally thought that "acid lick the esophagus and bite the pyloric antrum" [9]. However, gastric burns caused by alkali corrosives have been reported recently [4].

Patients with gastric outlet obstruction caused by corrosive ingestion usually require surgical intervention.

\section{Springer Open}

(c) The Author(s). 2021 Open Access This article is licensed under a Creative Commons Attribution 4.0 International License, which permits use, sharing, adaptation, distribution and reproduction in any medium or format, as long as you give appropriate credit to the original author(s) and the source, provide a link to the Creative Commons licence, and indicate if changes were made. The images or other third party material in this article are included in the article's Creative Commons licence, unless indicated otherwise in a credit line to the material. If material is not included in the article's Creative Commons licence and your intended use is not permitted by statutory regulation or exceeds the permitted use, you will need to obtain permission directly from the copyright holder. To view a copy of this licence, visit http://creativecommons.org/licenses/by/4.0/. 
The type of the surgery depends mostly on the findings during laparotomy [8]. Pyloroplasty and gastrojejunostomy are the most common surgical procedures described in the literature to relieve GOO [10].

In 1986, Tan and Bianchi reported the first use of a circum-umbilical incision to perform a pyloromyotomy for children with hypertrophic pyloric stenosis [11]. Excellent cosmetic results were reported after this approach $[12,13]$. During the past decade, this technique and its modifications have been used for treatment of a variety of surgical intra-abdominal diseases [14-20].

In this study, we investigated the feasibility and safety of Heinecke-Mikulicz pyloroplasty (HMP), through a circum-umbilical skin incision in children with pyloric/ antral stricture after accidental acid corrosive ingestion.

\section{Methods}

This prospective study included 11 patients presented with post-acid corrosive GOO during the period from May 2009 to May 2019.

Inclusion criteria included patients with GOO, who failed to respond to endoscopic dilatation. Children older than 10 years were excluded assuming that the approach will offer limited access after this age.

A data base chart was designed to collect the following data: sex, age at presentation, time between ingestion of corrosive material and hospital admission for surgery, nature of ingested substance, clinical features, diagnostic studies (contrast study and endoscopy), and response to previous trials of endoscopic dilatation, operative details, and postoperative outcome.

The parents or guardian of every patient had been informed about the details, pros, and cons of the operative technique, and a signed informed consent was obtained. Privacy of the participants and confidentiality of the data were maintained. The study was approved by IRB at our institution.

\section{Surgical technique}

All patients were operated under general endotracheal anesthesia and antibiotic prophylaxis. A nasogastric tube was inserted; suction of gastric contents and gastric wash with warm normal saline was done. The umbilicus was thoroughly cleansed with povidone-iodine. After standard skin preparation, a semicircular periumbilical incision was made (Fig. 1). A subcutaneous plane was developed for $3-5 \mathrm{~cm}$, the upper midline fascia was identified and exposed approximately one third to one half of the distance from the umbilicus to the xiphoid process, and then peritoneal cavity was opened through a midline vertical fascial incision (Fig. 2).

The pylorus was identified by first mobilizing the omentum with an opened moist sponge that is gently placed into the peritoneal cavity. By mobilizing the

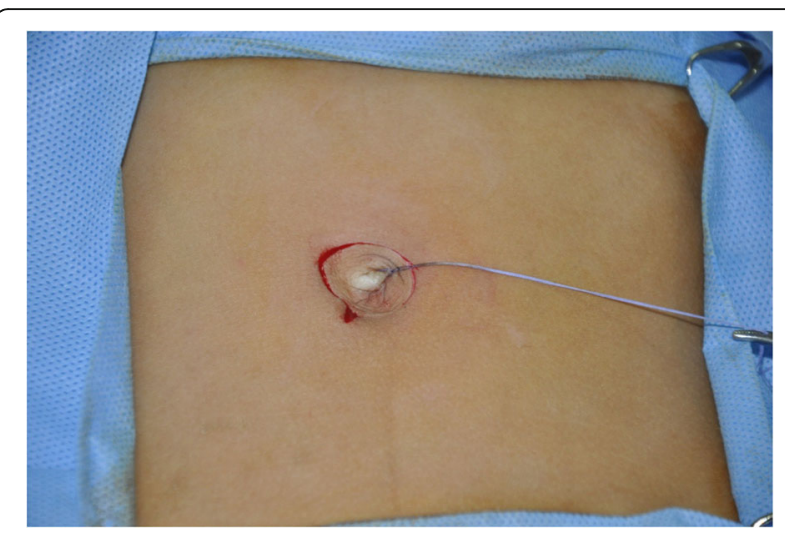

Fig. 1 Circum-umbilical skin incision

omentum, the transverse colon will be easily visualized in the wound. This maneuver brings the gastric antrum into view. In many cases, the dilated stomach was found just under the incised peritoneum. The greater curvature of the stomach was grasped with a moist sponge and the pylorus delivered by a gentle rocking movement (Fig. 3). All patients have variable degrees of fibrosis and scarring in the pylorus, which was contracted and rigid. Palpation reveals thickening in the gastric outlet region. Standard HMP was done. Between two traction sutures placed about $1 \mathrm{~cm}$ apart on the anterior surface of the pylorus, a longitudinal incision extending about $1-3 \mathrm{~cm}$ onto the antrum and a similar distance onto the duodenum. The incision was marked initially by diathermy needle (Fig. 4). The incision was created by fine tip needle diathermy for hemostasis. The total length of the incision ranged from 5 to $7 \mathrm{~cm}$. The initial entry into the gut lumen was made in the duodenum due to pyloric scaring. The longitudinal incision was closed transversely by one layer of interrupted 4/0 coated VICRYL ${ }^{\circ}$ (polyglactin 910) suture (Fig. 5). The suture line was covered by omentum. The midline fascia was closed by an interrupted $2 / 0$ polyglactin suture (Fig. 6). Finally, the skin incision was closed

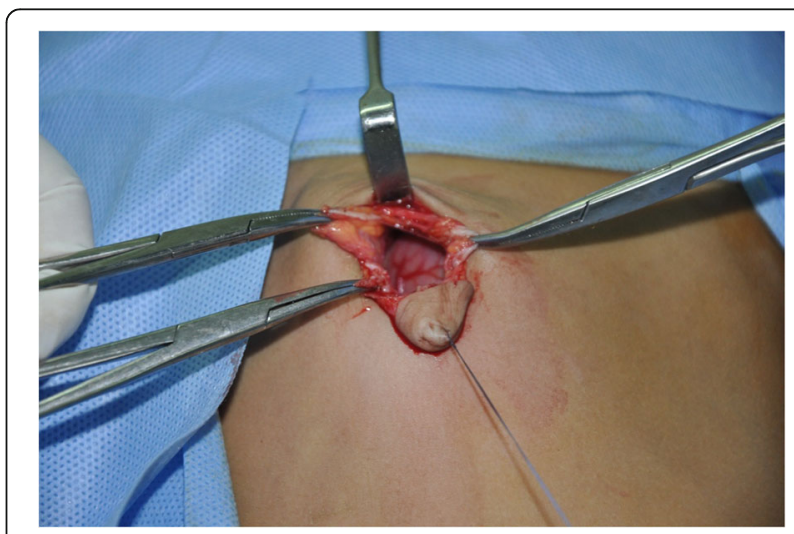

Fig. 2 Midline vertical fascial incision 


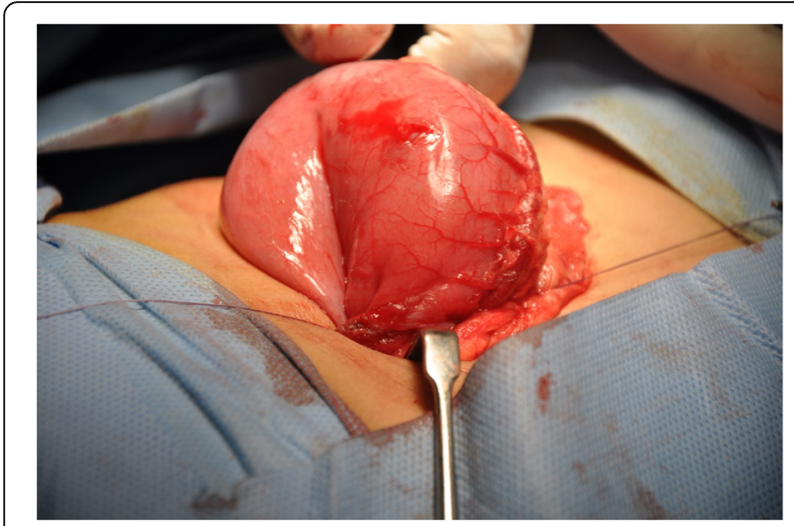

Fig. 3 Delivery of the dilated stomach from the incision

by a subcuticular 4/0 Vicryl suture (Fig. 7). No abdominal drain was used.

\section{Results}

The ages ranged from 17 months to 6 years with a median age of 3 years. The exact amount and concentration of the acid corrosive substance was not known.

The duration from ingestion to definitive surgery ranged from 2 to 6 months. The main symptoms were non-bilious vomiting, post-prandial abdominal distension, progressive weight loss, and constipation. Recurrent hematemesis occurred in two patients due to stasis gastritis and ulceration documented during upper gastrointestinal endoscopy.

Preoperative upper gastrointestinal (GIT) contrast study revealed variable degrees of gastric dilatation, pyloric stricture with delayed evacuation of the contrast material. Upper GIT endoscopy confirmed the diagnosis and attempts to dilate the stricture made whenever possible. Six patients were referred with recurrence of the pyloric stricture after repeated endoscopic trials. One patient developed both esophageal and pyloric stricture; the esophageal stricture responded to repeated

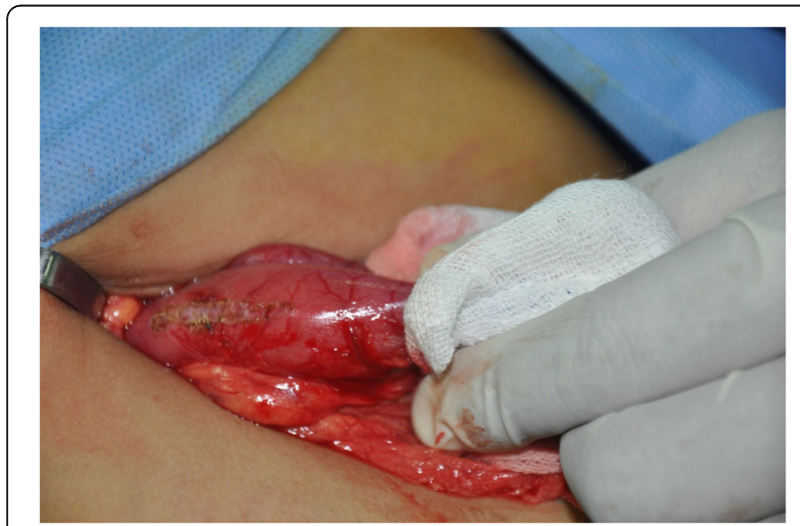

Fig. 4 Marking the site of incision for pyloroplasty by needle diathermy

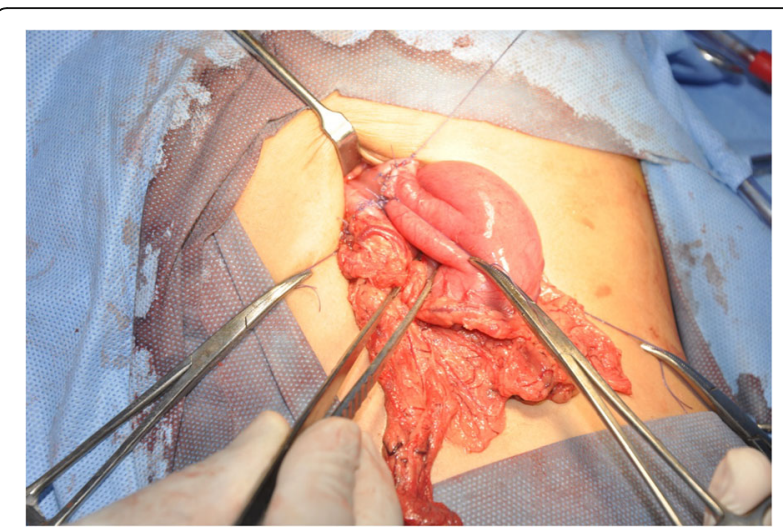

Fig. 5 The longitudinal incision was closed transversely by one layer interrupted suture

endoscopic dilatation while the pyloric stricture failed to respond to the repeated endoscopic dilatation. Four patients were referred for surgical intervention after the first unsuccessful endoscopic dilatation trial due to tight pyloric stricture.

\section{Operative results}

Delivery of the stomach and pylorus through the circum-umblical incision was successful in 10 patients. Longitudinal extension of the skin incision was needed in one patient due to difficulty in delivery of a hugely thickened stomach. The pylorus was grossly affected in 9 patients while both the pylorus and the gastric antrum were involved in 2 patients.

The HMP was feasible in all patients. The operating time ranged from 60 to $90 \mathrm{~min}$ (median $80 \mathrm{~min}$ ). The postoperative hospital stay was ranged from 5 to 7 days. Oral clear fluids were started on the second postoperative day. The vomiting stopped in 10 patients, who started to gain weight. The wound healed primarily without wound infection, wound dehiscence, or incisional hernia.

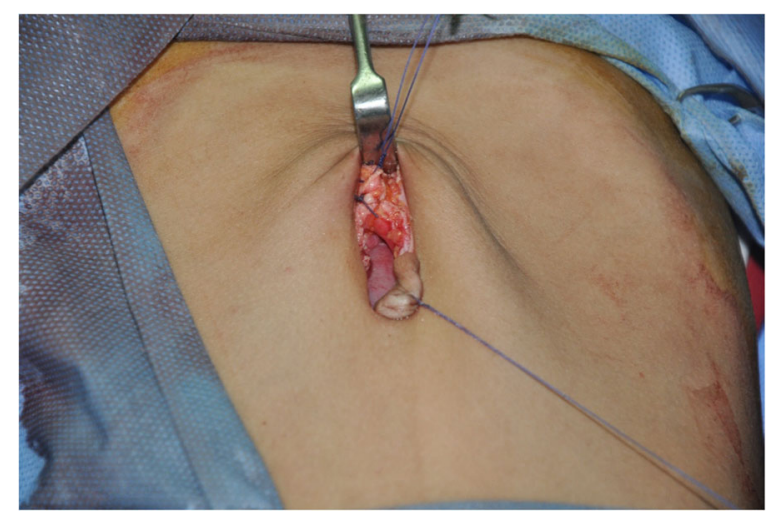

Fig. 6 Closure of facial incision 


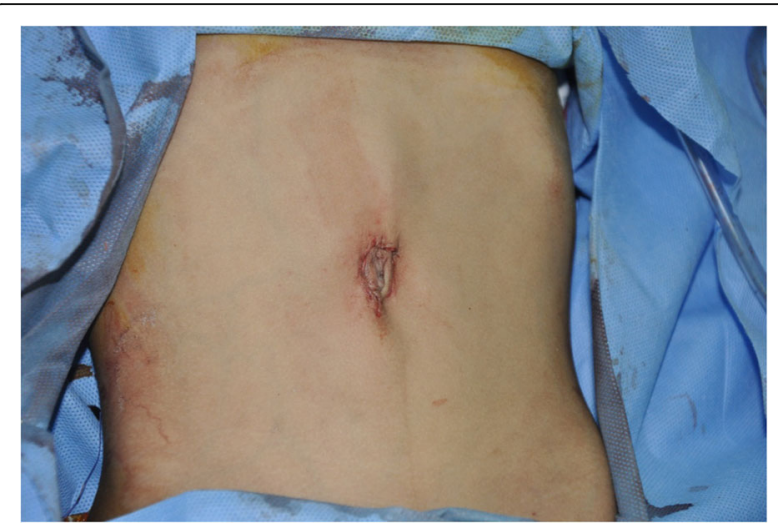

Fig. 7 Closure of the skin

One patient had a failure to gain weight with recurrent vomiting. Upper GIT endoscopy revealed recurrent pyloric stricture after 2 months. Gastrojejunostomy was done through a right upper transverse abdominal incision. The patient discharged from the hospital after 7 days. Follow-up for 1 year showed no recurrence of symptoms.

All patients were followed-up from 3 months to 7 years with a mean of 3.1 years. In all patients, the circumumblical incision left an almost undetectable scar and integrating well with the natural umbilical skin folds.

\section{Discussion}

Acid corrosive ingestion usually leads to gastric injury and pyloric stenosis $[4,7,8,21]$. Acids lead to coagulative necrosis of the pyloric region with subsequent segmental or extensive stricture formation while alkalis produce penetrating or liquifactive necrosis mainly in the oesophagus [22]. Acid is more likely than alkali to produce gastric injury [23]. Consequently, surgical intervention for gastric lesion is usually needed [24].

There are still some controversy regarding the appropriate timing and selection of surgical techniques. Previous studies have recommended pyloroplasty or gastrojejunostomy through exploratory incision, based on the location and extent of gastric injury $[4,7,21,25]$.

Since the seminal description of circum-umbilical approach by Tan and Bianchi in 1986 [11], the transumbilical approach was used for various intra-abdominal disorders of neonates, infants, and children due to elasticity of the abdominal wall $[19,20]$.

We have reported the versatility of transumbilical approach for management of various abdominal pathology in infants $[15,16]$. Our hypothesis was that such approach may be feasible in children with GOO following acid corrosive ingestion. In addition to the expected excellent cosmetic results, it could avoid the potential complications of wound healing after conventional upper transverse abdominal incision in this vulnerable group of nutritionally depleted children. To test this hypothesis, the current prospective study was planned.

We were concerned about two specific issues: [1] the feasibility of delivering, and returning back the dilated stomach and scarred pylorus through this incision in older children; and [2] the feasibility, safety, and efficacy of HMP in relieving of GOO when scaring is not limited to pylorus. In extensive fibrosis, we use another technique as finney pyloroplasty.

We found that the thin abdominal wall due to recent loss of weight with subsequent loss of subcutaneous fat, the semicircular skin incision, and the extended midline incision of the fascia have facilitated the delivery of pylorus through the cirum-umblical incision even in older children. This incision was feasible in all cases except one patient, who required further vertical extension of skin incision.

The current study showed also the feasibility and efficacy HMP as a surgical treatment of GOO in this group of patients. The longitudinal incision should be extended proximal to the scarred pyloric canal leading to a wide HMP.

It seems that HMP may not be the appropriate technique in cases of pyloric stricture with proximal extension of the scaring into the antrum. One of the two patients with antral scaring required redo surgery (gastrojejunostomy).

To the best of our knowledge, this is the first description of transumbilical pyloroplasty in the management of post-acid corrosive gastric outlet obstruction in children. Many publications have proven the lower risk of wound dehiscence after transumbilical pyloromyotomy for the management of hypertrophic pyloric stenosis in infants, even in those patients, who were nutritionally deprived due to prolonged vomiting [11-13]. Likewise, the feasibility and safety of this approach in the management of Hirschsprung's disease, ovarian cysts, and many other abdominal conditions have been reported, both in infants and older children [14-20].

The pyloroplasty has been conventionally performed through laparotomy incision. El-Asmar and Allam reported 26 patients with corrosive-induced gastric injury treated with different surgical techniques, postoperative anastomotic stricture requiring a second operation developed in one patient. Three deaths related to the associated esophageal strictures were reported in their series [10]. Ozokutan et al. reported 20 patients with GOO over 8 years; pyloroplasty was done in 5 patients, anastomotic stricture requiring a second operation developed in two of the 20 patients. There was no surgical mortality [21]. Ciftci et al. reported 11 patients with gastric outlet obstruction; pyloroplasty was done in 2 patients with no postoperative complications [4]. In the current study, 
recurrent stricture developed in one patient, no mortalities occurred.

None of the previously published articles has focused on the abdominal wound [4-10] to enable us to compare objectively between trans-umbilical vs the conventional laparotomy approach in terms of abdominal wound healing and its potential complications. However, based on the results of the current study, it seems that one of the main advantages of this technique is minimizing the incidence of wound dehiscence, which may be a real risk after surgery for nutritionally debilitated children with gastric outlet obstruction.

One of the attractive alternatives to the current transumblical approach is laparoscopy. Recently, Seleim et al. [26] reported laparoscopic diamond antroduodenostomy in 5 patients with GOO as a consequence of caustic liquid ingestions. The average operative time in the laparoscopic group is comparable to the current transumbilcal study (81 vs 80 minuses). No anastomotic leak occurred in both studies. However, postoperative delayed gastric emptying was noted in 2 cases in laparoscopic-treated group. A comparable postoperative hospital stay 5-7 days was noted. This shows that the current transumbilical approach is an attractive minimal invasive approach compared to laparoscopy in the absence of required facilities and expertise to conduct laparoscopy safety in this group of patients.

The results of HMP through the circum-umblical approach are quite encouraging. However, the small numbers of patients and the lack of control group represent limitations of the current study. Future studies with larger numbers of patients are recommended.

Heinecke-Mikulicz pyloroplasty through a circumumbilical approach is feasible and safe in the majority of children with post-acid corrosive GOO. It is associated with satisfactory wound healing and excellent cosmetic outcome. The cosmetic and functional results compare favorably or surpass conventional laparotomy or laparoscopy for pyloroplasty.

\section{Abbreviations \\ GOO: Gastric outlet obstruction; HMP: Heinecke-Mikulicz pyloroplasty; GIT: Gastrointestinal}

\section{Acknowledgements}

Not applicable.

\section{Authors' contributions}

$1-E$. $E$ is the chief surgeon and contributed to the study design, review, and approval of the final version of the manuscript. 2-N A, HA, I E, and $\mathrm{HH}$ participated in the surgery and following-up of the patients, collected the patients' data and analyzed them, wrote initial draft, and approved the final version of the manuscript. 3-D S performed the endoscopic diagnosis, trials of dilatation and assessment, collected the endoscopic data and analyzed them, and approved the final version of the manuscript. The authors read and approved the final version of the manuscript.

\section{Funding}

None
Availability of data and materials

The related data and material of the current study are available from the corresponding author on a reasonable request.

\section{Ethics approval and consent to participate}

This study was approved by the Research Ethics Committee at our institution on September 2009, \# 335/9/2009. A written informed consent for participation at this study was obtained from parents/guardians.

\section{Consent for publication}

A written consent for publication of the results of this study was obtained from parents/guardians.

\section{Competing interests}

The authors declare that they have no competing interests

\section{Author details}

${ }^{1}$ Pediatric Surgery, Faculty of Medicine, Tanta University Hospital, Tanta University, Tanta, Egypt. ${ }^{2}$ Pediatric Gastroenterology, Tanta Faculty of Medicine, Tanta, Egypt.

Received: 21 February 2020 Accepted: 4 February 2021

Published online: 09 March 2021

References

1. Lakshmi CP, Vijayahari R, Kate V, Ananthakrishnan N. A hospital-based epidemiological study of corrosive alimentary injuries with particular reference to the Indian experience. Natl Med J India. 2013;26:31-6.

2. Urganci N, Usta M, Kalyoncu D, Demirel E. Corrosive substance ingestion in children. Indian J Pediatr. 2014;81:675-9.

3. Contini S, Scarpignato C. Caustic injury of the upper gastrointestinal tract: a comprehensive review. World J Gastroenterol. 2013;19:3918-30.

4. Ciftci AO, Senocak ME, Buyukpamukcu N, Hicsonmez A. Gastric outlet obstruction due to corrosive ingestion: incidence and outcome. Pediatr Surg Int. 1999;15:88-91.

5. Gillis DA, Higgins G, Kennedy R. Gastric damage from ingested acid in children. J Pediatr Surg. 1985;20:494-6.

6. Hall RJ, Lilly JR. Treatment of acid burns of the stomach in children by pedicle pyloroplasty. Surg Gynecol Obstet. 1988;167:152-4.

7. Ozcan C, Ergun O, Sen T, Mutaf O. Gastric outlet obstruction secondary to acid ingestion in children. J Pediatr Surg. 2004;39:1651-3.

8. Tekant G, Eroglu E, Erdogan E, Yesildag E, Emir H, Buyukunal C, et al. Corrosive injury-induced gastric outlet obstruction: a changing spectrum of agents and treatment. J Pediatr Surg. 2001;36:1004-7.

9. Marks IN, Banks $S$, Werbeloff $L$, et al. The natural history of corrosive gastritis: report of five cases. Am J Dig Dis. 1963;8:509-24.

10. El-Asmar K, Allam A. Surgical management of corrosive-induced gastric injury in children: 10 years' experience. J Pediatr Surg. 2018;53:744-7.

11. Tan KC, Bianchi A. Circumumbilical incision for pyloromyotomy. Br J Surg. 1986:73:399.

12. Lazar D, Naik B, Fitch M, Nuchtern J, Brandt M. Transumbilical pyloromyotomy with umbilicoplasty provides ease of access and excellent cosmetic results. J Pediatr Surg. 2008;43:1408-10.

13. Cozzi D, Ceccanti S, Mele E, Frediani S, Totonelli G, Cozzi F. Circumumbilical pyloromyotomy in the era of minimally invasive surgery. J Pediatr Surg. 2008;43:1802-6.

14. Sauer CJ, Langer JC, Wales PW. The versatility of the umbilical incision in the management of Hirschsprung's disease. J Pediatr Surg. 2005;40:385-9.

15. Elhalaby E, Hussam S, Hassan HH, Hashish MS. Hashish A, The versatility of the transumbilical approach for laparotomy in infants. Ann Pediatr Surg. 2015;11:1-6.

16. Hashish A. Minimally invasive surgery for ovarian cysts in children: transumbilical versus laparoscopic approach. Ann Pediatr Surg. 2011;7:11722.

17. Abdelkader HM, Abd-ElLatif M, El-Asmar K. Can the modified Tan-Bianchi circumumbilical approach be used for treating older children? Ann Pediatr Surg. 2011;7:126-9.

18. Lin JY, Lee ZF, Chang YT. Transumbilical management for neonatal ovarian cysts. J Pediatr Surg. 2007:42:2136-9. 
19. Soutter AD, Askew AA. Transumbilical laparotomy in infants: a novel approach for a wide variety of surgical disease. J Pediatr Surg. 2003;38:9502

20. Yuki T, Kosaku M, et al. A new paradigm of scarless abdominal surgery in children: transumbilical minimal incision surgery. J Pediatr Surg. 2014;49: 1605-9.

21. Ozokutan BH, Ceylan H, Ertaskin I, Yapici S. Pediatric gastric outlet obstruction following corrosive ingestion. Pediatr Surg Int. 2010;26:615-8.

22. Chibishev A, Simonovska N, Shikole A. Post-corrosive injuries of upper gastrointestinal tract. Prilozi. 2010;31:297-316.

23. Subbarao KS, Kakar AK, Chandrasekhar V, Ananthakrishnan N, Banerjee AL. Cicatrical gastric stenosis caused by corrosive ingestion. Aust N Z J Surg. 1988:58:143-6.

24. Chaudhary A, Puri AS, Dhar P, Reddy P, Sachdev A, Lahoti D, et al. Elective surgery for corrosive-induced gastric injury. World J Surg. 1996;20:703-6.

25. Kaushik R, Singh R, Sharma R, Attri AK, Bawa AS. Corrosive-induced gastric outlet obstruction. Yonsei Med J. 2003;44(6):991-4.

26. Seleim HM, Wishahy AK, Abouelfadl MA, Farouk MM, Elshimy K, Fares A, Kaddah SN, Eltagy G, Elbarbary M. Laparoscopic diamond antroduodenostomy for postcorrosive pyloric cicatrization: a nove approach. J LAPAROENDOSCOPIC \& ADVANCED SURGICAL TECHNIQUES. 2019:29(4):1-4.

\section{Publisher's Note}

Springer Nature remains neutral with regard to jurisdictional claims in published maps and institutional affiliations.

\section{Submit your manuscript to a SpringerOpen ${ }^{\circ}$ journal and benefit from:}

- Convenient online submission

- Rigorous peer review

- Open access: articles freely available online

High visibility within the field

- Retaining the copyright to your article

Submit your next manuscript at $\boldsymbol{\nabla}$ springeropen.com 